\title{
Age-specific diabetes risk by the number of metabolic syndrome components: a Korean nationwide cohort study
}

\author{
Min-Kyung Lee ${ }^{1}$, Kyungdo Han ${ }^{2}$ and Hyuk-Sang Kwon ${ }^{3^{*}}$ (1)
}

\begin{abstract}
Background: Metabolic syndrome is associated with an increased risk of diabetes. This study investigated the associations between the number of metabolic syndrome components and diabetes risk by age, sex and BMI.

Methods: Data for 19,475,643 participants $\geq 20$ years old with no history of diabetes were obtained between 2009 and 2012 and were accessed using the South Korean National Health Insurance Service. Metabolic syndrome was defined according to the modified criteria of the National Cholesterol Education Program Adult Treatment Panel III. We assessed the risk of diabetes according to the number of metabolic syndrome components after stratifying the study participants into groups by age (20-39, 46-64, $\geq 65$ years), sex, and BMI (below or above 25).
\end{abstract}

Results: During an average of 5.13 years of follow-up, the incidence rates of diabetes increased with the number of metabolic syndrome components. Age and BMI gradually increased with the number of metabolic syndrome components. The multivariable-adjusted hazard ratios (HRs) for incident diabetes were 1.401, 1.862, 2.47, 3.164 and 4.501 for participants with one through five components, respectively, compared with those without metabolic syndrome components. The risk of diabetes was 1.79-, 2.18-, and 3.05-times higher for participants $\geq 65$ years; $2.57-, 3.45-$, and 5.18-times higher for participants 40-64 years; and 2.55-, 3.89-, and 6.31-times higher for participants 20-39 years of age with three through five components, respectively, compared to those with no components. There was no difference in the risk of diabetes between men and women. The HRs were 5.63 for participants with a BMI $\geq 25$ and 3.98 for those with a $\mathrm{BMI}<25$ among individuals with five components.

Conclusions: The risk of diabetes was more strongly associated with the number of metabolic syndrome components among younger adults. In addition, the risk of diabetes across the number of metabolic syndrome components was greater in participants with a $\mathrm{BMI} \geq 25$.

Keywords: Metabolic syndrome, Risk factors, Diabetes mellitus, Type 2

\section{Background}

Metabolic syndrome is a general term given to a clustering of hyperglycaemia, obesity, dyslipidaemia and hypertension [1] and is known to increase the risk for type 2

\footnotetext{
*Correspondence: drkwon@catholic.ac.kr

${ }^{3}$ Division of Endocrinology and Metabolism, Department of Internal Medicine, Yeouido St. Mary's Hospital, College of Medicine, The Catholic University of Korea, Seoul, Republic of Korea

Full list of author information is available at the end of the article
}

diabetes and cardiovascular disease $[2,3]$. The prevalence of metabolic syndrome is increasing worldwide and this trend has also been observed in Korea [4]. The desired clinical response to metabolic syndrome is improved health outcomes through comprehensive management of the core components of metabolic syndrome [5].

Diabetes risk has been shown to increase with the number of metabolic syndrome components [6-8]. The estimated prevalence of metabolic syndrome differs by age, sex, and ethnicity because variations exist in the 
frequencies of metabolic components [9-12]. Therefore, the risk of diabetes according to the number of metabolic syndrome components could be different by age, sex, and obesity status. Few studies, however, have analysed diabetes risk in relation to the number of metabolic syndrome components. In addition, the prevalence of metabolic syndrome components increases with age, but the increase in young adults is marked [13]. The presence of metabolic syndrome could represent a lifetime of increased diabetes risk [14]. Moreover, the early identification of metabolic syndrome components could lead to targeted interventions to prevent the development of the syndrome, and thus reduce diabetes risk in later life. Here, we focused on age-specific diabetes risk as a function of the number of metabolic syndrome components to effectively predict the development of diabetes.

In the present large-scale study of a Korean cohort, we investigated the association of the number of metabolic syndrome components at baseline with the development of diabetes over a 5-year period. We also prospectively evaluated the risk of diabetes within particular subgroups based on combinations of age, sex, and obesity status.

\section{Methods}

\section{Study subjects}

We used the database provided by the South Korean National Health Insurance Service (NHIS), a populationbased cohort including nearly all South Korean citizens [15]. The database contains all inpatient and outpatient medical claims data including personal information, prescription drugs, diagnostic and treatment codes, and primary and additional diagnostic codes. This study was approved by the NHIS inquiry commission and adhered to the tenets of the Declaration of Helsinki for biomedical research. Since 2015, the South Korean NHIS has released a nationally representative dataset that is open to all researchers whose study protocols are approved by an official review committee. Informed consent was waived by the Institutional Review Board of The Catholic University of Korea (No. SC18ZESI0047) because the national insurance claim data were deidentified for the analysis.

From this cohort, the data collected from 23,317,567 participants over 20 years old between January 2009 and December 2012 were extracted. We excluded 59,805 participants with data missing for at least one variable, as well as 3,782,119 patients with type 2 diabetes. Ultimately, the final study population consisted of $19,475,643$ people who had at least one reexamination over 5 years and for whom values for all metabolic syndrome components were measured at baseline. For each participant, the primary outcome between January 1, 2013 and December 31, 2017 was type 2 diabetes, and the number of person-years of follow-up was determined.

\section{Definition of metabolic syndrome and diagnosis of type 2 diabetes}

According to the revised National Cholesterol Education Program Adult Treatment Panel III (NCEP ATP III) criteria $[16,17]$, metabolic syndrome was diagnosed when three or more of the following five criteria were met: (1) abdominal obesity (waist circumference $[\mathrm{WC}] \geq 90 \mathrm{~cm}$ for men or $85 \mathrm{~cm}$ for women) [18]; (2) elevated triglycerides (fasting triglycerides $\geq 150 \mathrm{mg} / \mathrm{dl}$ ) or on drug treatment for elevated triglycerides at baseline; (3) reduced HDL cholesterol $(<40 \mathrm{mg} / \mathrm{dl}$ for men and $<50 \mathrm{mg} / \mathrm{dl}$ for women); (4) elevated blood pressure (BP) $(\geq 130 \mathrm{mmHg}$ systolic $\mathrm{BP}, \geq 85 \mathrm{mmHg}$ diastolic $\mathrm{BP}$, and/or on antihypertensive drug treatment at baseline, and/or a history of hypertension); and (5) elevated fasting glucose ( $\geq 100 \mathrm{mg} / \mathrm{dl}$ or on drug treatment for elevated glucose).

Type 2 diabetes was present if claims for anti-diabetes drugs were found in the database according to the following criteria: (1) at least one claim per year under the 10th revision of the International Classification of Diseases (ICD)-10 codes E11 (noninsulin-dependent diabetes mellitus), E12 (malnutrition-related diabetes mellitus), E13 (other specified diabetes mellitus), or E14 (unspecified diabetes mellitus), (2) at least one claim per year for antidiabetes medication prescription, or (3) fasting plasma glucose (FPG) level $\geq 126 \mathrm{mg} / \mathrm{dl}$.

\section{Measurements and definitions of covariates}

Physical examination was performed by measuring height, weight, WC, systolic BP, and diastolic BP according to standardized methods. WC $(\mathrm{cm})$ was measured at the midpoint between the lower border of the rib cage and the iliac crest by trained examiners. BP was measured in triplicate and the mean value of the second and third measurements was used for the analysis. BMI was calculated as weight in kilograms divided by height in square metres $\left(\mathrm{kg} / \mathrm{m}^{2}\right)$. Blood samples for the measurement of FPG, HDL cholesterol, and triglyceride levels were obtained in the morning after an overnight fast. Hospitals where these health examinations were performed were certified by the NHIS and subjected to regular quality control.

All participants were required to complete self-administered questionnaires that inquired about smoking and alcohol habits, physical activity, and past medical history. Smoking habits were divided into current smoking and noncurrent smoking. Heavy alcohol consumption was defined as the consumption of $\geq 30$ g per day. Regular exercise was defined as performing more than $30 \mathrm{~min}$ of moderate physical activity at least five times per week or more than 75 min of strenuous physical activity at least three times per week [19]. Income level was categorized based on the monthly health insurance premiums paid 
and the population was divided into four income levels. The lowest income population was categorized as the variable.

\section{Statistical analysis}

The baseline characteristics of the participants are presented as mean \pm standard deviation (SD) or proportions (\%). Geometric means (95\% confidence intervals) are used for the distribution that was heavily skewed. 95\% CI calculated using Wald method for means. The ageand sex-adjusted incident rates for type 2 diabetes were calculated. Cox proportional hazards regression models were used to estimate hazard ratios (HRs) and 95\% CIs for incident diabetes with the adjustment of important risk factors, such as age, sex, alcohol consumption, smoking status, exercise, income, and BMI. The proportional hazard assumption of Cox models was examined by plotting the log minus log survival curves and survival times against cumulative survival. Stratified analyses were performed by age (20-39 vs. 40-64 vs. $\geq 65$ years of age), sex (men vs. women), and BMI (below vs. above $25 \mathrm{~kg} / \mathrm{m}^{2}$ ), and interactions between subgroups were tested. All statistical tests were two-sided, and $\mathrm{P} \leq 0.05$ was considered to be statistically significant. All analyses were performed using the Statistical Analysis System statistical software package (version 9.4; SAS Institute, Inc., Cary, NC, USA).

\section{Availability of data and materials}

The authors are unable to share the data analysed in this study because the Korean National Health Insurance Service (NHIS) owns the data. Researchers can request access on the NHIS website (https://nhiss.nhis.or.kr). Details of this process and a provision guide are now available at http://nhiss.nhis.or.kr/bd/ab/bdaba000en g.do.

\section{Results}

\section{General baseline characteristics}

The baseline characteristics of the study population stratified according to the number of metabolic syndrome components are shown in Table 1. Of a total of 19,475,643 participants (9,783,377 men and 9,692,266 women), $6,269,899$ (29.7\%) had zero components of metabolic syndrome, 5,574,829 (27.4\%) had 1, 3,907,472 (20.4\%) had 2, 2,389,166 (13.3\%) had 3, 1,083,306 (7.1\%) had 4, and $250,971(2.1 \%)$ had 5 . The mean ages of the participants with zero through five components at baseline were $39.69 \pm 12.02,45.02 \pm 13.31,48.83 \pm 13.36,51.86 \pm 13.26$, $54.42 \pm 13.05$ and $56.62 \pm 12.56$ years, respectively. BMI, WC, triglyceride levels, BP, and FPG gradually increased and HDL cholesterol decreased as the number of metabolic syndrome components increased.
Association between the number of metabolic syndrome components at baseline and diabetes risk during follow-up During an average 5.13 years of follow-up, 1,906,963 subjects were diagnosed with type 2 diabetes. Table 2 shows the incidence rates and HRs of type 2 diabetes according to the number of metabolic syndrome components at baseline. The age- and sex-adjusted incidence rates of developing diabetes were 10.86, 15.53, 21.35, 29.14, 38.69 and 56.65 per 1000 person-years for participants with zero through five components at baseline, respectively. After adjusting for age, sex, alcohol consumption, smoking status, exercise, income, and BMI, the multivariableadjusted HRs for developing diabetes were 1.401 (95\% CI 1.394-1.409), 1.862 (95\% CI 1.852-1.872), 2.47 (95\% CI 2.456-2.484), 3.164 (95\% CI 3.144-3.184) and 4.501 (95\% CI 4.466-4.537) for participants with one to five components at baseline, respectively, compared to those with no components (Table 2).

\section{Diabetes risk according to the number of metabolic syndrome components stratified by age, sex, and BMI}

The incidence rates of diabetes according to the number of metabolic syndrome components after stratification of study participants into groups based on age (20-39, $40-64, \geq 65$ ), sex (men vs. women), and BMI (below or above 25) are shown in Fig. 1. The incidence rates of diabetes were 34.72, 42.91, 51.07, 61.14, 73.93, and 102.76 per 1000 person-years for participants $\geq 65$ years; 9.73 , $15.35,22.94,34.07,49.69$, and 79.19 for participants $40-64$ years; and $2.96,4.23,6.99,12.28,21.23$, and 37.6 for participants 20-39 years of age, respectively. The incidence rates among women were higher than those among men with two or more components. There was no difference in incidence rates according to the number of metabolic syndrome components stratified by BMI.

Figure 2 shows the risk of developing diabetes according to the number of metabolic syndrome components among individuals stratified by age, sex, and BMI. The interaction between metabolic syndrome components and subgroups (age, sex, and BMI) is statistically significant $(\mathrm{P}<0.0001)$. Multivariable-adjusted hazard ratios for incident diabetes among individuals with one through five components at baseline were 1.23, 1.48, 1.79, 2.18, and 3.05 for participants $\geq 65$ years; $1.39,1.88,2.57,3.45$, and 5.18 for participants $40-64$ years; and 1.24, 1.69, $2.55,3.89$, and 6.31 for participants $20-39$ years of age, respectively, compared to those with no components. The risks of diabetes were the highest in the 40-64 year age group among participants with one or two components and in the 20-39 year age group among those with four or five components. Diabetes risk was the lowest in the $\geq 65$-year age group for all numbers of components. 


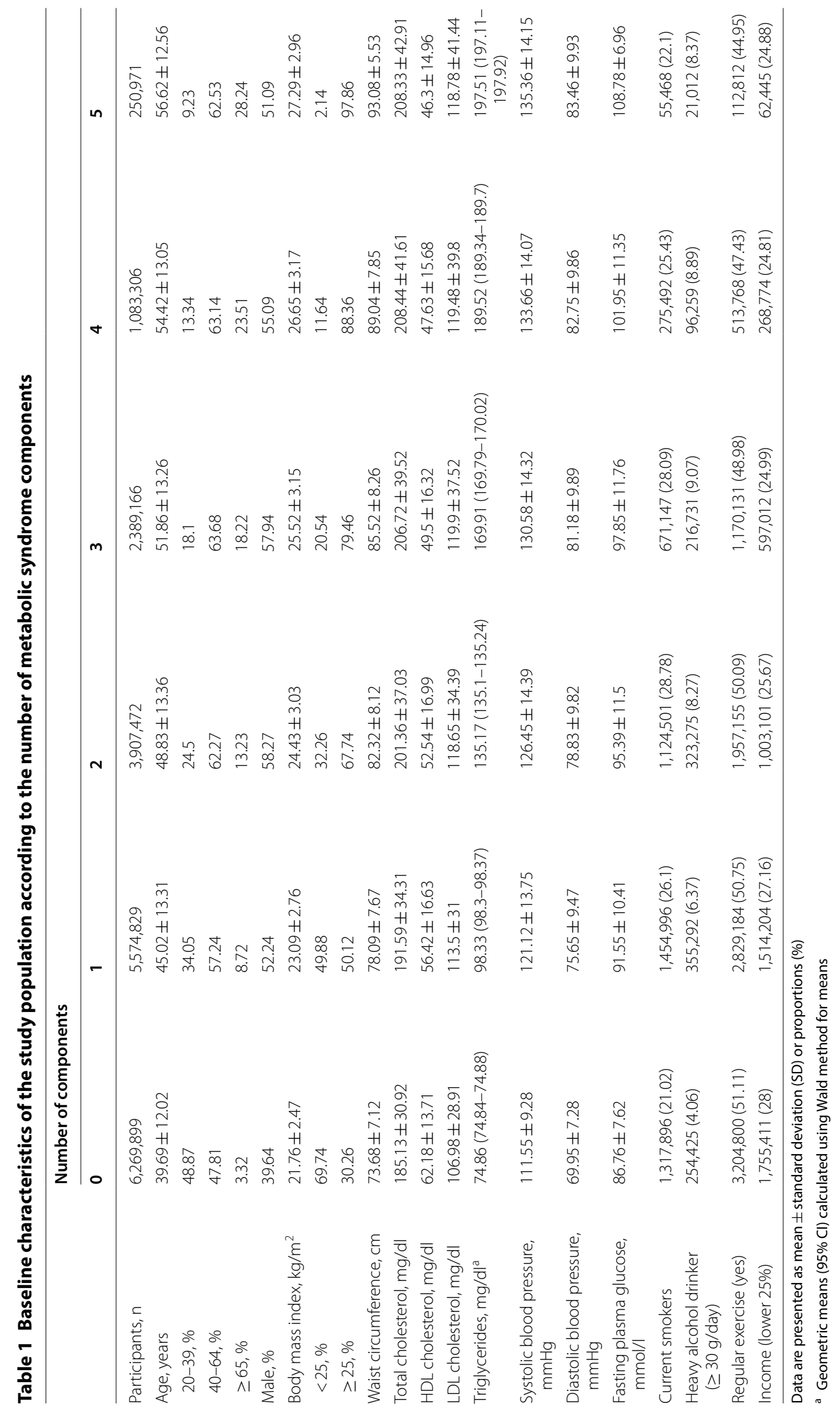


Table 2 Multivariable-adjusted hazard ratios for developing diabetes according to the number of metabolic syndrome components

\begin{tabular}{|c|c|c|c|c|c|c|c|}
\hline & \multicolumn{6}{|c|}{ Number of components } & \multirow[t]{2}{*}{ Trend $\mathrm{P}$} \\
\hline & 0 & 1 & 2 & 3 & 4 & 5 & \\
\hline Cases, $\mathrm{n}$ & 218,603 & 385,479 & 455,944 & 426,612 & 303,566 & 116,759 & \\
\hline $\begin{array}{l}\text { Follow-up duration } \\
\text { (person-years) }\end{array}$ & $31,043,596.21$ & $28,642,155.32$ & $20,577,529.59$ & $12,419,916.48$ & $5,887,174.59$ & $1,415,272.2$ & \\
\hline $\begin{array}{l}\text { Crude incidence rate } \\
\text { (per } 1000 \text { person- } \\
\text { years) }\end{array}$ & 7.0418 & 13.4584 & 22.1574 & 34.349 & 51.564 & 82.4993 & \\
\hline $\begin{array}{l}\text { Age- and sex-adjusted } \\
\text { incidence rate (per } \\
1000 \text { person-years) }\end{array}$ & 10.8634 & 15.5303 & 21.3481 & 29.1435 & 38.6941 & 56.6539 & \\
\hline Adjusted HR $(95 \% \mathrm{Cl})$ & 1 (ref.) & $1.401(1.394,1.409)$ & $1.862(1.852,1.872)$ & $2.47(2.456,2.484)$ & $3.164(3.144,3.184)$ & $4.501(4.466,4.537)$ & $<0.0001$ \\
\hline
\end{tabular}

a Adjusted for age, sex, alcohol consumption, smoking status, exercise, income, and BMI

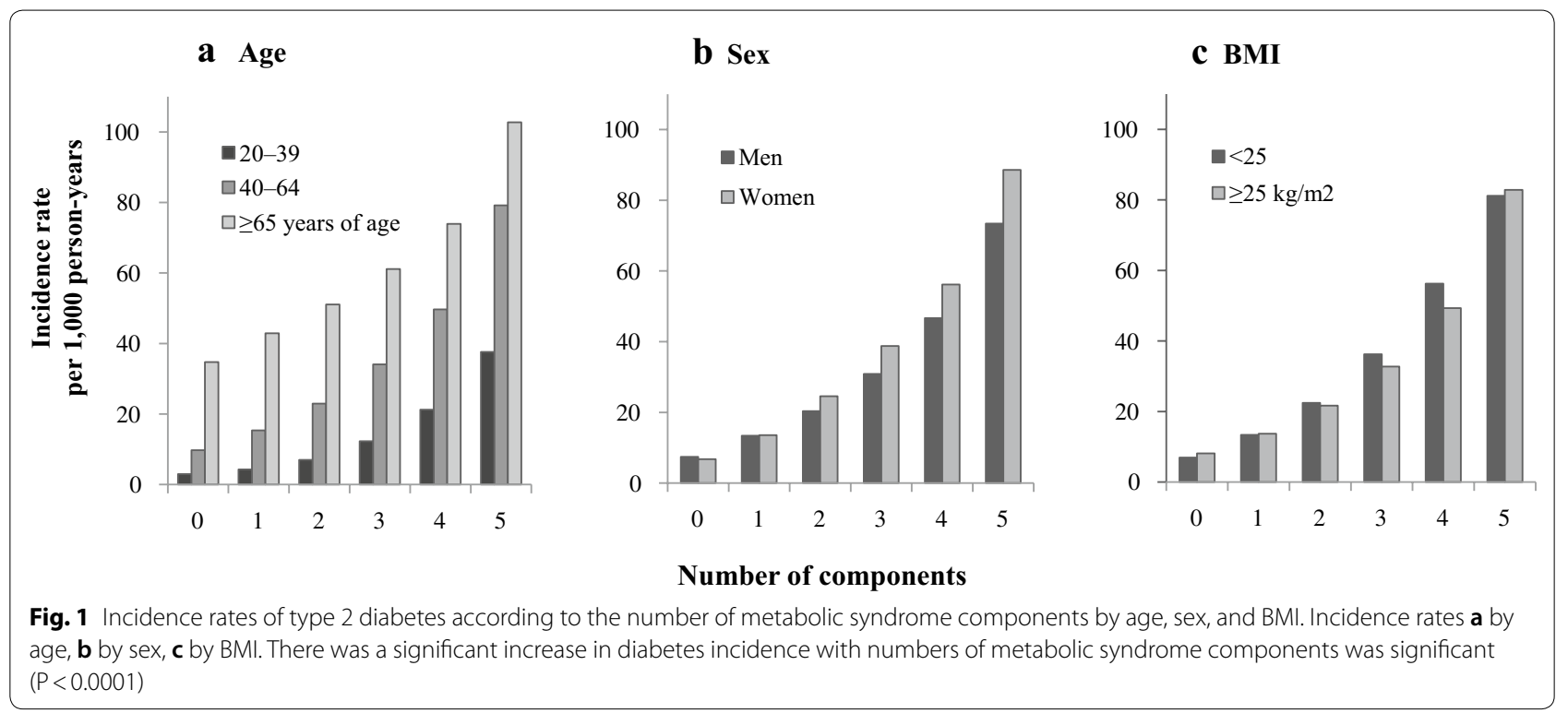

There was no difference in diabetes risk according to the number of metabolic syndrome components between men and women. The risk of diabetes across the number of metabolic syndrome components was greater in participants with a $\mathrm{BMI} \geq 25$ than in those with a $\mathrm{BMI}<25$. Multivariable-adjusted hazard ratios for incident diabetes in individuals with five components were 5.63 for participants with a BMI $\geq 25$ and 3.98 for those with a $\mathrm{BMI}<25$.

\section{Discussion}

In this large-scale prospective cohort study of 19.5 million adult Korean participants, we investigated the association between diabetes risk and the number of metabolic syndrome components by age, sex, and BMI. The number of metabolic syndrome components at baseline was significantly associated with an increased risk of diabetes over a 5-year period, independent of sociodemographic characteristics. The risk of diabetes was more strongly associated with the number of metabolic syndrome components among younger adults. In addition, the risk of diabetes across the number of metabolic syndrome components was greater in individuals with a BMI $\geq 25$.

Our findings suggest that the number of metabolic syndrome components provides additional value for predicting the development of diabetes. Several studies have confirmed that metabolic syndrome, regardless of its definition, is a significant predictor of diabetes in various populations [20]. Previous studies have also shown that diabetes risk increases with the number of metabolic syndrome components [6-8]. In the present study, diabetes 


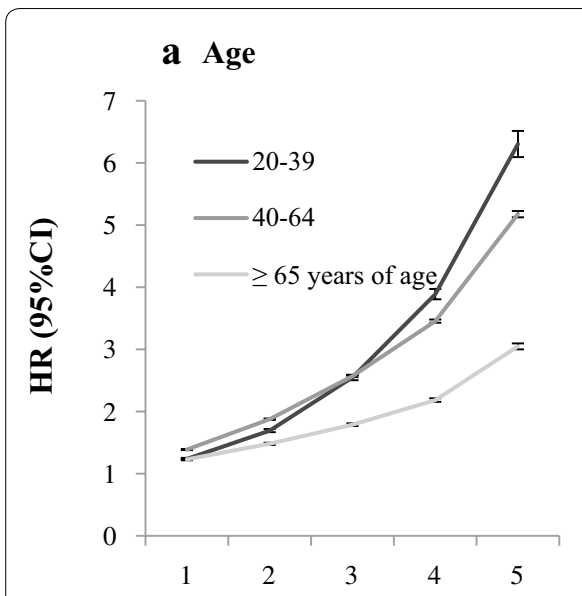

b Sex

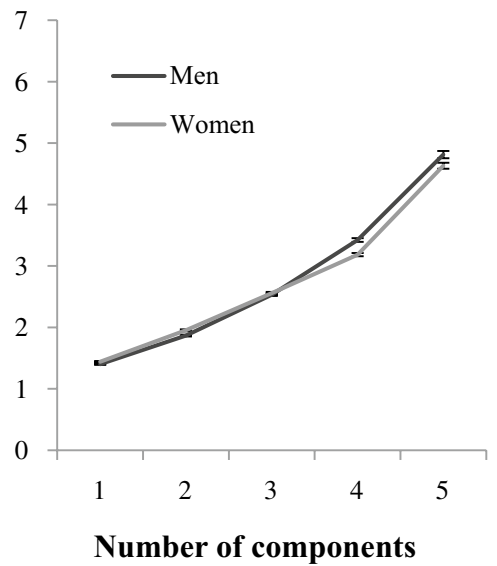

c BMI

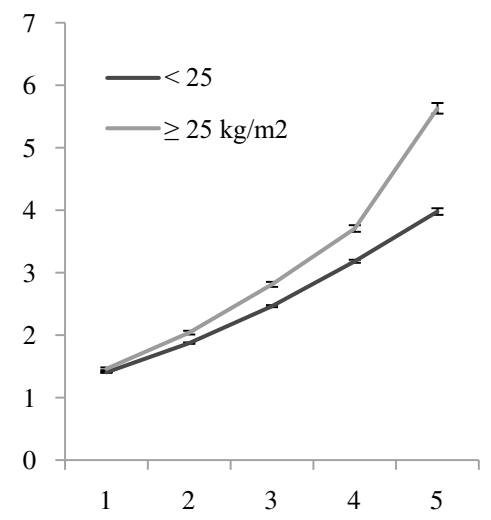

Fig. 2 Hazard ratios $(95 \% \mathrm{Cl})$ of type 2 diabetes according to the number of metabolic syndrome components by age, sex, and BMI. Hazard ratios $\mathbf{a}$ by age, $\mathbf{b}$ by sex, and $\mathbf{c}$ by BMI. The interaction between metabolic syndrome components and subgroups (age, sex, and BMI) is statistically significant $(\mathrm{P}<0.0001)$. There was a significant increase in diabetes risk with numbers of metabolic syndrome components $(P<0.0001)$. Multivariable hazard ratios were adjusted for age, sex, alcohol consumption, smoking status, exercise, income, and BMI. Error bars represent upper $95 \% \mathrm{Cl}$

risk increased with the number of metabolic syndrome components. The presence of only one metabolic syndrome component was significantly associated with diabetes risk compared to the presence of no components.

We prospectively examined the risk of diabetes according to the number of metabolic syndrome components by age, sex, and BMI. There was a significant increase in diabetes incidence with increasing numbers of metabolic syndrome components. When participants were divided into three age groups (20-39, 40-64, $\geq 65$ years), the incidence rates of diabetes were highest for individuals $\geq 65$ years old and were lowest for participants 20-39 years old across all numbers of components. Diabetes risk was more strongly associated with the number of metabolic syndrome components among younger individuals. There was no significant difference in the incidence rate or risk of diabetes between men and women.

As expected, the number of metabolic syndrome components was positively correlated with age. The incidence rates of diabetes were greater in older adults; however, the risk of diabetes by number of metabolic syndrome components was higher in young adults. Among participants with five components, the risk of incident diabetes was 6.31-times higher for people 20-39 years of age, 5.18-times higher for participants 40-64 years, and 3.45times higher for participants $\geq 65$ years than for those without metabolic syndrome components. These findings suggest that the number of metabolic syndrome components is important, particularly for young adults with metabolic syndrome. As the prevalence of type 2 diabetes in the young adult population is dramatically increasing
$[21,22]$, it is important to identify individuals who have a high risk of developing type 2 diabetes in this age group.

The major predisposing risk factors of type 2 diabetes among young adults are obesity, family history, and sedentary lifestyle factors such as physical activity, diet, smoking, and alcohol consumption [23, 24]. A study revealed that obesity, family history, hypertension and dyslipidaemia were independent risk factors for earlyonset type 2 diabetes [25]. These risk factors are similar to those associated with later-onset type 2 diabetes [26]. Early-onset type 2 diabetes leads to a longer lifetime exposure to hyperglycaemia and consequently more severe long-term complications [27]. Additionally, the course of early-onset type 2 diabetes could be more rapid and disruptive than that of older-onset type 2 diabetes, leading to early morbidity and poor quality of life [28]. Therefore, it is warranted to apply early lifestyle interventions to prevent the development of type 2 diabetes in young adults with metabolic syndrome components.

BMI is strongly and independently associated with the risk of type 2 diabetes [29, 30]. We evaluated the risk of diabetes across the number of metabolic syndrome components by BMI status. We observed that the risk of diabetes across the number of metabolic syndrome components was greater in individuals who were overweight or obese than in those who had normal BMIs. Moreover, we examined the association between the number of metabolic syndrome components and diabetes risk after adjustment for BMI. The number of metabolic syndrome components was associated with an increased risk of diabetes after adjustment for traditional risk factors such 
as age, sex, alcohol consumption, smoking status, exercise, income, and BMI. The use of waist circumference to assess abdominal adiposity is superior to that of BMI. WC is a better predictor of metabolic syndrome than BMI and is widely used in the definition of metabolic syndrome [17, 31]. WC is more strongly associated with an increased risk of type 2 diabetes and cardiovascular disease than BMI $[32,33]$. In this study, after adjusting for risk factors, including BMI, the association remained significant. This association was independent of the risk predicted by increased BMI. Our findings showed an independent correlation of WC, but not BMI, with obesity-related diabetes risk. We should screen for WC as well as BMI since the early detection of individuals with metabolic abnormalities may be beneficial in the prevention of diabetes.

The strengths of our study include its longitudinal population-based design, a sufficient number of type 2 diabetes events, a high follow-up rate, and a nationally representative data set. However, the present study has some limitations that could be addressed by further investigation. First, the diagnosis of metabolic syndrome was based on a single measurement at baseline, similar to the method used in other epidemiological studies. The number of metabolic syndrome components of individuals may have changed during the follow-up period because of lifestyle factors and medications; therefore, risk estimates may also have changed. Second, because type 2 diabetes was defined based on the prescription of anti-diabetes drugs and the presence of relevant ICD-10 codes, type 2 diabetes patients who were not diagnosed prior to the analysis might have been misclassified as not having diabetes. Third, although we adjusted for potential confounding factors, we could not completely exclude reverse causality or the effects of unmeasured confounding factors. Finally, the data represent outcomes of South Korean citizens, a homogenous ethnic population, and this study population may be considered a limitation in regard to generalizability. Further large-scale prospective studies are required to verify these results in other populations.

\section{Conclusion}

Our stratified analysis indicated that younger adults had a higher risk of diabetes across the number of metabolic syndrome components than older adults. These results imply that early prevention and intervention of metabolic syndrome components particularly in young adults are important. In addition, the risk of diabetes according to the number of metabolic syndrome components was greater in obese individuals. Our findings indicate that age and BMI-specific risk stratification by the number of metabolic syndrome components can identify individuals with a high risk of developing diabetes.

\begin{abstract}
Abbreviations
NHIS: National Health Insurance Service; NCEP ATP III: National Cholesterol Education Program Adult Treatment Panel III; WC: waist circumference; HDL: high density lipoprotein; BP: blood pressure; BMI: body mass index; FPG: fasting plasma glucose; TC: total cholesterol; LDL: low density lipoprotein.
\end{abstract}

\section{Acknowledgements}

The authors would like to thank the two reviewers for their constructive feedback on the manuscript.

\section{Authors' contributions}

$\mathrm{MKL}, \mathrm{KDH}$, and HSK contributed to the study design, analysis, and interpretation of data. MKL drafted and edited the manuscript. HSK provided supervision and revised the manuscript. KDH performed the statistical analysis of data. All authors read and approved of the final manuscript.

\section{Funding}

This research was funded by the Basic Science Research Program through the National Research Foundation of Korea (NRF) funded by the Ministry of Education (2018R1D1A1B07049079).

\section{Availability of materials and data}

The data that support the findings of this study are available from the National Health Insurance Service but restrictions apply to the availability of these data, which were used under license for the current study, and so are not publicly

available. Access to the dataset can be obtained through the Health Insurance Data Service home page (http://nhiss.nhis.or.kr).

\section{Ethics approval and consent to participate}

This study was approved by the NHIS inquiry commission and adhered to the tenets of the Declaration of Helsinki for biomedical research. Informed consent was not required because the national insurance claim data were deidentification for the analysis. This study was also approved by the Institutional Review Board of The Catholic University of Korea (No. SC18ZESIO047).

\section{Consent for publication}

Not applicable

\section{Competing interests}

The authors declare no competing interests.

\section{Author details}

${ }^{1}$ Division of Endocrinology and Metabolism, Department of Internal Medicine, Myongji Hospital, Hanyang University College of Medicine, Goyang, Gyeonggi-do, Republic of Korea. ${ }^{2}$ Department of Medical Statistics, College of Medicine, The Catholic University of Korea, Seoul, Republic of Korea. ${ }^{3}$ Division of Endocrinology and Metabolism, Department of Internal Medicine, Yeouido St. Mary's Hospital, College of Medicine, The Catholic University of Korea, Seoul, Republic of Korea.

Received: 5 September 2019 Accepted: 18 December 2019 Published online: 27 December 2019

\section{References}

1. Expert Panel on Detection, Evaluation, and Treatment of High Blood Cholesterol in Adults. Executive summary of the third report of The National Cholesterol Education Program (NCEP) expert panel on detection, evaluation, and treatment of high blood cholesterol in adults (Adult Treatment Panel III). JAMA. 2001;285:2486-97.

2. Sattar N, McConnachie A, Shaper AG, Blauw GJ, Buckley BM, de Craen AJ, et al. Can metabolic syndrome usefully predict cardiovascular disease and diabetes? Outcome data from two prospective studies. Lancet. 2008;371:1927-35. 
3. Hwang YC, Jee JH, Oh EY, Choi YH, Lee MS, Kim KW, et al. Metabolic syndrome as a predictor of cardiovascular diseases and type 2 diabetes in Koreans. Int J Cardiol. 2009;134:313-21.

4. Lim S, Shin H, Song JH, Kwak SH, Kang SM, Won Yoon J, et al. Increasing prevalence of metabolic syndrome in Korea: the Korean National Health and Nutrition Examination Survey for 1998-2007. Diabetes Care. 2011;34:1323-8.

5. Shin JA, Lee JH, Lim SY, Ha HS, Kwon HS, Park YM, et al. Metabolic syndrome as a predictor of type 2 diabetes, and its clinical interpretations and usefulness. J Diabetes Investig. 2013;4:334-43.

6. Nakanishi N, Takatorige T, Fukuda H, Shirai K, Li W, Okamoto M, et al. Components of the metabolic syndrome as predictors of cardiovascular disease and type 2 diabetes in middle-aged Japanese men. Diabetes Res Clin Pract. 2004;64:59-70.

7. Mukai N, Doi Y, Ninomiya T, Hata J, Yonemoto K, Iwase M, et al. Impact of metabolic syndrome compared with impaired fasting glucose on the development of type 2 diabetes in a general Japanese population: the Hisayama study. Diabetes Care. 2009;32:2288-93.

8. Nichols GA, Moler EJ. Diabetes incidence for all possible combinations of metabolic syndrome components. Diabetes Res Clin Pract. 2010;90:115-21.

9. Razzouk L, Muntner P. Ethnic, gender, and age-related differences in patients with the metabolic syndrome. Curr Hypertens Rep. 2009;11:127-32.

10. Hildrum B, Mykletun A, Hole T, Midthjell K, Dahl AA. Age-specific prevalence of the metabolic syndrome defined by the International Diabetes Federation and the National Cholesterol Education Program: the Norwegian HUNT 2 study. BMC Public Health. 2007;7:220.

11. Ilanne-Parikka P, Eriksson JG, Lindström J, Hämäläinen $H$, Keinänen-Kiukaanniemi S, Laakso M, et al. Prevalence of the metabolic syndrome and its components: findings from a Finnish general population sample and the Diabetes Prevention Study cohort. Diabetes Care. 2004;27:2135-40.

12. Damiri B, Abualsoud MS, Samara AM, Salameh SK. Metabolic syndrome among overweight and obese adults in Palestinian refugee camps. Diabetol Metab Syndr. 2018;10:34.

13. Nolan PB, Carrick-Ranson G, Stinear JW, Reading SA, Dalleck LC. Prevalence of metabolic syndrome and metabolic syndrome components in young adults: a pooled analysis. Prev Med Rep. 2017;7:211-5.

14. Marott SC, Nordestgaard BG, Tybjaerg-Hansen A, Benn M. Components of the metabolic syndrome and risk of type 2 diabetes. J Clin Endocrinol Metab. 2016;101:3212-21.

15. Lee J, Lee JS, Park SH, Shin SA, Kim K. Cohort profile: the National Health Insurance Service-National Sample Cohort (NHIS-NSC), South Korea. Int J Epidemiol. 2017:46:e15.

16. Alberti KG, Eckel RH, Grundy SM, Zimmet PZ, Cleeman JI, Donato KA, et al. Harmonizing the metabolic syndrome: a joint interim statement of the International Diabetes Federation Task Force on Epidemiology and Prevention; National Heart, Lung, and Blood Institute; American Heart Association; World Heart Federation; International Atherosclerosis Society; and International Association for the Study of Obesity. Circulation. 2009:120:1640-5.

17. Grundy SM, Cleeman JI, Daniels SR, Donato KA, Eckel RH, Franklin BA, et al. Diagnosis and management of the metabolic syndrome: an American Heart Association/National Heart, Lung, and Blood Institute Scientific Statement. Circulation. 2005:112:2735-52.
18. Lee SY, Park HS, Kim DJ, Han JH, Kim SM, Cho GJ, et al. Appropriate waist circumference cutoff points for central obesity in Korean adults. Diabetes Res Clin Pract. 2007:75:72-80.

19. Piercy KL, Troiano RP. Physical activity guidelines for Americans From the US Department of health and human services. Circ Cardiovasc Qual Outcomes. 2018;11:e005263.

20. Ford ES, Li C, Sattar N. Metabolic syndrome and incident diabetes: current state of the evidence. Diabetes Care. 2008;31:1898-904.

21. Ha KH, Kim DJ. Trends in the diabetes epidemic in Korea. Endocrinol Metab (Seoul). 2015;30:142-6.

22. Cho NH, Shaw JE, Karuranga S, Huang Y, da Rocha Fernandes JD, Ohlrogge AW, et al. IDF Diabetes Atlas: global estimates of diabetes prevalence for 2017 and projections for 2045. Diabetes Res Clin Pract. 2018;138:271-81.

23. Wilmot E, Idris I. Early onset type 2 diabetes: risk factors, clinical impact and management. Ther Adv Chronic Dis. 2014;5:234-44.

24. Alberti G, Zimmet P, Shaw J, Bloomgarden Z, Kaufman F, Silink M, et al. Type 2 diabetes in the young: the evolving epidemic: the international diabetes federation consensus workshop. Diabetes Care. 2004:27:1798-811.

25. Yu H, Xie L-F, Chen K, Yang G-Y, Xing X-Y, Zhao J-J, et al. Initiating characteristics of early-onset type 2 diabetes mellitus in chinese patients. Chin Med J. 2016;129:778-84

26. Siegel KR, Bullard KM, Imperatore G, Ali MK, Albright A, Mercado Cl, et al. Prevalence of major behavioral risk factors for type 2 diabetes. Diabetes Care. 2018;41:1032-9.

27. Hillier TA, Pedula KL. Complications in young adults with early-onset type 2 diabetes: losing the relative protection of youth. Diabetes Care. 2003:26:2999-3005.

28. Lascar N, Brown J, Pattison H, Barnett AH, Bailey CJ, Bellary S. Type 2 diabetes in adolescents and young adults. Lancet Diabetes Endocrinol. 2018;6:69-80.

29. Narayan KM, Boyle JP, Thompson TJ, Gregg EW, Williamson DF. Effect of BMI on lifetime risk for diabetes in the U.S. Diabetes Care. 2007;30:1562-6.

30. Ganz ML, Wintfeld N, Li Q, Alas V, Langer J, Hammer M. The association of body mass index with the risk of type 2 diabetes: a case-control study nested in an electronic health records system in the United States. Diabetol Metab Syndr. 2014;6:50.

31. Alberti KG, Zimmet P, Shaw J. Metabolic syndrome-a new world-wide definition. A Consensus Statement from the International Diabetes Federation. Diabetic Med. 2006;23:469-80.

32. Ohlson LO, Larsson B, Svardsudd K, Welin L, Eriksson H, Wilhelmsen L, et al. The influence of body fat distribution on the incidence of diabetes mellitus. 13.5 years of follow-up of the participants in the study of men born in 1913. Diabetes. 1985;34:1055-8.

33. Rexrode KM, Carey VJ, Hennekens CH, Walters EE, Colditz GA, Stampfer $\mathrm{MJ}$, et al. Abdominal adiposity and coronary heart disease in women. JAMA. 1998;280:1843-8.

\section{Publisher's Note}

Springer Nature remains neutral with regard to jurisdictional claims in published maps and institutional affiliations.

Ready to submit your research? Choose BMC and benefit from

- fast, convenient online submission

- thorough peer review by experienced researchers in your field

- rapid publication on acceptance

- support for research data, including large and complex data types

- gold Open Access which fosters wider collaboration and increased citations

- maximum visibility for your research: over 100M website views per year

At BMC, research is always in progress.

Learn more biomedcentral.com/submissions 